\section{O estudo da vegetação xeromórfica e xerofítica na região Centro-Ocidental Paranaense}

\section{The study of xeric and xerophytic vegetation in the region West-Central Paranaense}

Resumo: As áreas pesquisadas estão localizadas na região Centro-Ocidental Paranaense, microrregião geográfica de Cianorte e de Campo Mourão, no Estado do Paraná, nos municípios de Campo Mourão, Luiziana e Tuneiras do Oeste. As espécies de cerrado (savana) e as plantas das famílias Cactaceae e Bromeliaceae são consideradas formações paleoclimáticas que destoam da vegetação e das condições climáticas atuais, essas espécies aparecem, nessas regiões, em manchas. A pesquisa iniciou-se a partir das discussões de pesquisadores que indicam essas espécies como bioindicadoras de condições ecológicas passadas e sua base está fundamentada na interpretação da teoria dos refúgios florestais. Os resultados obtidos demonstraram que esses redutos estudados seriam, então, testemunhos deste ciclo de clima seco.

\section{Paranaense}

Abstract: The areas investigated are located in the Central-Western Paranaense region , geographical and micro-region of Cianorte, Campo Mourão in Paraná State, in the municipalities of Campo Mourão, Luiziana and Tuneiras do Oeste. The species of cerrado ( savanna), as well as household plants cactaceous Bromeliad and paleoclimatic formations are considered to detract from the vegetation and current weather conditions these species appear in these regions in patches. The research started from the discussions of researchers indicate that these species as bioindicators of past ecological conditions and its base is reasoned on the interpretation of the Theory of Forest Refuges. The results were that these redoubts studied, guarded evidences of a past dry climate cycle, remaining in places with characteristics that favor the persistence of this xeromorfic and xerophytic vegetation.
Lucimara Liberali*

Maria Eugênia Moreira Costa Ferreira **

*Doutora em Geografia pela Universidade Estadual de Maringá (UEM).

** Doutora em Geografia pela Universidade de São Paulo (USP). Professora Associada na UEM.

\section{Palavras-chave:}

Teoria dos refúgios florestais; fitogeografia; condições paleoclimática.

Key-Words:

Theory of forest refuges, phytogeography, paleoclimatic conditions. 


\section{Introdução}

A fitogeografia do estado do Paraná apresenta enclave que marca a paisagem com especies vegetais fitofisionomica xeromórfica e xerofítica, destacando os municípios de Campo Mourão, Luiziana e Tuneiras do Oeste. Neste contexto, a paisagem é marcada por diversas peculiaridades. Mas, no presente estudo, fez-se um recorte fitogeográfico para espécies de formações abertas, compreendendo cerrados e áreas com presença de plantas das famílias Cactaceae e Bromeliaceae, particularmente, de espécies associadas aos climas pretéritos. Esses fragmentos biológicos caracterizam-se como relictos do Quaternário Antigo (Maack, 1981). Dentre os municípios com vegetação ligada a ambientes que tiveram paleoclima mais secos, pode-se citar os da área de estudo, situados nos municípios de Campo Mourão, Luiziana e Tuneiras do Oeste.

A presença de espécies caracterizadoras de condições ambientais diferentes da atual chamou a atenção desta pesquisa, especialmente quanto ao entendimento da distribuição e permanência de espécies de cerrado (savana), de Cactaceae e Bromeliaceae em áreas em que as condições ecológicas e climáticas não são condizentes com o ambiente próprio para o desenvolvimento destas plantas. O interesse em realizar esses estudos, prende-se ainda ao fato de estas espécies peculiares estar inseridas na floresta estacional semidecidual e floresta ombrófila mista, nos municípios de Campo Mourão, Luiziana e Tuneiras do Oeste.

O estudo da fitogeografia de enclave com espécies de Bromeliaceae Cactaceae e cerrado (savana) teve início a partir das discussões de pesquisadores. Estes apresentam essas espécies como bioindicadores de condições ecológicas passadas. Sua base está fundamentada na interpretação da teoria dos refúgios florestais.

A partir de estudos teóricos e práticos, analisou-se a distribuição e a adaptação da vegetação associada ao semiúmido e ao semiárido encontradas na região de estudo. Para tanto, realizou-se o levantamento fitogeográfico, como forma de caracterizar a vegetação nessas áreas ecotonais e com enclaves de vegetação desconforme com as condições climáticas e as formações florestais atuais.Aplicou-se a teoria dos refúgios florestais e interpretaram-se os "documentos" relativos a elementos biológicos e sua interação com elementos abióticos (solos, clima, relevo). Por fim,procedeu-se à busca de explicação da dinâmica atual do complexo vegetacional, sustentada pelas mudanças ambientais do Quaternário, especialmente entre 13.000-18.000 anos.

Para Liberali (2014) considera-se que as Cactáceas, as Bromeliáceas e espécies de Cerrado surgiram nesses locais, por ocasião dos períodos ciclicos. Esses periodos são aferidos nas regiões Sul e Sudeste do Brasil, por meio dos estudos palinológicos, "mostram um clima geral semiárido, entre 28.000 e 11.000 anos A.P.(antes do presente), tanto no planalto como na planície" e os mamíferos fósseis indicam uma ocorrência de biomas abertos e florestas no Quaternário no sul do Brasil, variando de acordo com as flutuações climáticas (BOLZON e MARCHIORI, 2002).

Esse período propiciou condições ambientais locais favoráveis às suas formações e permanência, fixando-se em áreas hoje atípicas às condições climáticas, formando enclaves na area de estudo, estado do Paraná.

Geografia Ensino \& Pesquisa, v. 18, n.2 p. 163-174, maio/ago. 2014

O estudo da vegetação xeromórfica e xerofítica na região CentroOcidental Paranaense

\section{Caracterização da área de estudo}

pA localização da área de estudo pode ser observada na Figura 1. Os referidos pontos apresentam a localização exata dos fragmentos biológicos na área de estudo contidos nos municípios de Campo Mourão, Luiziana e Tuneiras do Oeste. No município de Araruna, que re- 
presenta a faixa de transição, não foram encontrados bioindicadores dessa formação. Portanto, na região, observa-se que os enclaves de vegetação, associada ao semiúmido e ao semiárido, apresentam-se como pontos isolados e aparentemente descontínuos.

Contudo, a ação humana A ação do homem, dentro do contexto de colonização, causou a devastação da paisagem original. Esse processo teve a colaboração de outros fatores, exemplifica o relevo da região ao apresentar topografia pouco acentuada e solo com boa aptidão agrícola. Ao mesmo tempo, tais elementos beneficiaram o desenvolvimento e as expansões agrícola e pecuária.Concomitante, ocorreua expansão demográfica, resultando na substituição da cobertura vegetal, na sua quase totalidade, inclusive a área de campos cerrados (savana) que cobriam grande parte do atual espaço urbano, neste caso, no municipio de Campo Mourão.

Quanto aos aspectos geológicos, morfológico, pedológicos e climático, a formação geológica dos municípios de Campo Mourão e Luiziana é marcada pelas rochas basálticas constituída da maior manifestação de errupções magmáticas, por fissura, do mundo (MAACK, 1981), em transição com as rochas de arenito formadas pelo processo de sedimentação eólica no município de Tuneiras do Oeste (Bigarella, 1964). Esses municípios apresentam uma paisagem marcada por grandes derrames de lavas vulcânicas. As últimas compõem as rochas de basalto e constituem: o grupo São Bento da formação Serra Geral, os processos de sedimentação eólica e formam as rochas de arenito, constituindo o grupo Bauru da formação Arenito Caiuá

Figura 1 - Localização dos Municípios de Tuneiras do Oeste, Campo Mourão e Luiziana

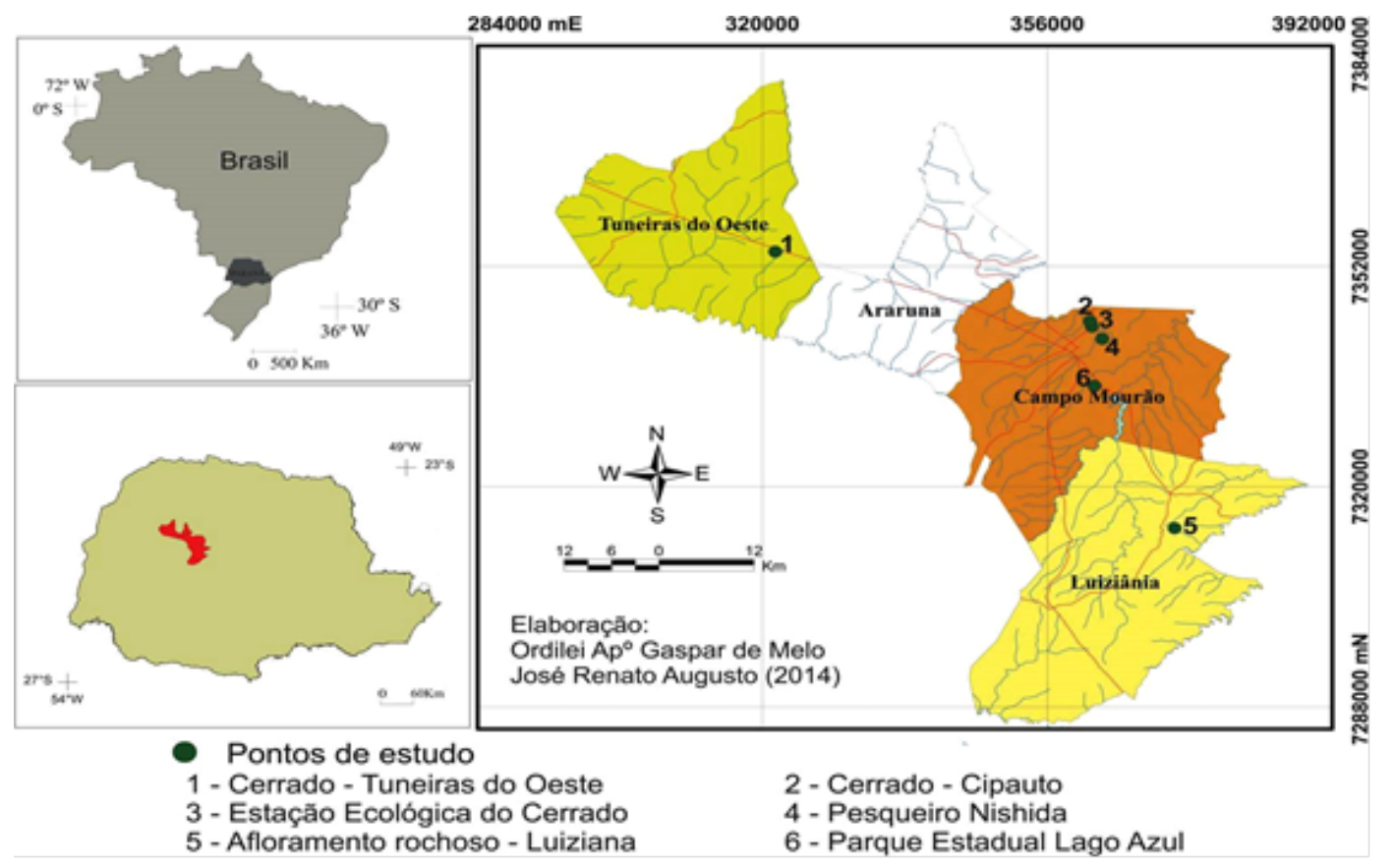

Fonte: Ordilei Gaspar de Melo e Jose Renato Augusto

Os municípios de Campo Mourão e Luiziana apresentam um relevo variando entre260 (mínima) e 840 (máxima) m. s. n. m. Predominam as formas: topos aplainados, vertentes retilíneas e côncavas na base, e vales em calha, modeladas em rochas da Formação Serra Geral (MINEROPAR, 2006).

O município de Tuneiras do Oeste apresenta um relevo variando entre 240 (mínima) e Geografia Ensino \& Pesquisa, v. 18, n.2 p. 163-174, maio/ago. 2014 660 (máxima) m. s. n. m. As formas predominantes são topos alongados e aplainados, vertentes convexas e vales em "V", modeladas em rochas da Formação Caiuá (MINEROPAR, 2006). 
pais unidades pedológicas compostas dos solos: Nitossolos, Latossolos Vermelho Distroférrico, Cambissolos e Neossolos Lítolicos, apresentando uma textura argilosa (EMBRAPA, 2008).

No município de Tuneiras do Oeste as rochas de arenito formam as principais unidades pedológicas com os solos: Latossolos Vermelhos, Argissolos, Gleissolos e Neossolos Quartzarênicos. Estes apresentam uma textura arenosa (EMBRAPA, 2008).

Portanto, as formações vegetais desses municípios ocorrem em litologias variadas, sobre diferentes unidades pedológicas sendo mais comuns em Latossolos, Argissolos, Nitossolos, Cambissolos e Neossolos Líticos (RODERJAN et.al 2002).

Quanto ao clima nos municípios estudados, recorreu-se à análise na área da Mesorregião Geográfica Centro-Ocidental paranaense, elaborada por Massoquim (2010). Segundo a autora, fazendo uma análise das linhas de transição, e nesse caso, referindo-se à área de pesquisa Luiziana a Tuneiras do Oeste, [...] “A precipitação oscila entre 1600 a $1800 \mathrm{~mm}$ ”, para Luiziana, e de "a 1400 a1600 mm anuais para o município de Tuneiras do Oeste" [...] e as temperaturas médias anuais são de $23^{\circ} \mathrm{C}$, sendo a média do mês mais quente superior a $26^{\circ} \mathrm{C}$ e a do mês mais frio, inferior a $18^{\circ} \mathrm{C}^{\prime \prime}$.

\section{Materiais e métodos}

O procedimento básico da pesquisa iniciou-se a partir das abordagens teórico- conceituais, enfocando vários autores aptos, de certa forma, a contribuir para o melhor entendimento das teorias que permeiam a temática desta tese.

Neste sentido, a base teórica das discussões fundamentou-se nos seguintes autores: Bolzon e Marchiori, (2002), Haffer, (1992), Hueck, (1972), Ab’Saber (1962, 1971,1977, 1992, 2002) Viadana (2000), Haffer e Prance, (2002) Bigarella, et. al., (1994), Bigarella, (1964), e Maack, (1981). Os citados pesquisadores dão subsídio para sustentar os estudos da distribuição geográfica das plantas atuais e a influência paleoflorística. As implicações e as transformações paleovegetais, no espaço e no tempo, especialmente no período Quaternário, chamam a atenção pela complexidade da geobiocenose no biótopo. Na sequência, deu-se início aos procedimentos operacionais relacionados ao uso de técnicas e materiais que auxiliaram no desenvolvimento do estudo de campo e gabinete.

Neste sentido, foi importante o estudo de reconhecimento das áreas, da distribuição das espécies portadoras de aspecto fitofisionômico em condições ecológicas diferente das atuais. Realizou-se uma caracterização geral dos aspectos geológicos, geomorfológicos, pedológicos e climatológicos das seis áreas estudadas - vegetação de cerrado (savana), pequenas áreas de Cactaceae e Bromeliaceae - nos municípios de Campo Mourão, Luiziana e Tuneiras do Oeste, no Estado do Paraná.

O levantamento fitogeográfico das espécies de fitofisionomia xerofítica e xeromórfica, para identificação das espécies, efetivou-se por meio da coleta do material botânico. Para a coleta das plantas, fez-se necessário elaboração de exsicatas. Este material esta depositado no herbário da Estação Ecológica do Cerrado e da UTFPR - Campus Campo Mourão.

Geografia Ensino \& Pesquisa, v. 18 n. 2 p. $163-174$, maio/ago. 2014

O estudo da vegetação xeromórfica e xerofítica na região CentroOcidental Paranaense

\section{A teoria dos refúgios florestais para interpretação da vegetação xerofitica e xe- romorfica nos municípios de Campo Mourão, Luiziana e Tuneiras do Oeste}

A Teoria dos refúgios apresentada por Vanzolini (1970), Ab’Sáber (1969), Haffer (1969) foi proposta no sentido de entender a diversidade biológica da Amazônia. Essa teoria é 
aceita há décadas, na tentativa de explicar a distribuição e ocorrência de formações e espécies que apresentam fitofisionomias desconformes com as condições ecológicas atuais.

Dentre os autores que contestam essa teoria, esta Colinvaux (2000), que afirma em seu estudo no Lago Pata (floresta Amazônica), que a teoria de refugio de vegetação de cerrado é muito instável e, por isso, é tratada mais como uma hipótese. Contudo, não descarta totalmente o conceito fundamentado pelos autores acima mencionados.

Knapp (2003) ao discutir sobre a teoria dos refúgios, afirma que a coisa mais sensata a se fazer é não tentar apoiar uma teoria ou outra, mas realizar levantamentos e descobrir a dinâmica das espécies que vivem nas florestas neotropicais e como estão distribuídas.

As implicações e as transformações paleovegetais no espaço e no tempo, especialmente no período Quaternário, chama atenção pela complexidade da geobiocenose no biotopo. Para explicar essas complexidades no contexto vegetacional a base metodológica está enfocada na interpretação da teoria dos refúgios.

A teoria dos refúgios é um importante instrumento na interpretação da dinâmica da fitogeografia no espaço e no tempo no Holoceno e suas implicações na formação e nas organizações e (re)organizações da paisagem florística. Segundo Troppmair (2006), a metodologia de variação das geobiocenoses no espaço e no tempo tem como finalidade determinar a retração e expansão do cerrado (savana), bromélias e cactáceas em afloramentos rochosos.

Em seus estudos biogeográficos, Troppmair (2006) baseia-se na definição de Stoddart (1974) e define a geobiocenose como sendo "um sistema de interações em funcionamento composto de um ou mais organismos vivos e seus ambientes reais, tanto físico como biológico". O Quaternário, no contexto fitogeográfico, e suas influências no biótopo trazem em seu bojo as diversas transformações na paisagem florística marcada pelos períodos cíclicos glaciais e interglaciais.

A teoria dos refúgios é um importante mecanismo para explicar a dinâmica fitogeográfica, especialmente no Brasil que é país de condição climática tropical que influencia diretamente na riqueza florística. Portanto, esta é marcada pela heterogeneidade de formações. Essa dinâmica fitogeográfica apresenta como já dissemos anteriormente, uma disparidade de formações como vegetação de cerrado (savana), bromeliácea e cactáceas, que estão em ambientes adversos às suas condições ecológicas, especialmente da flora.

A teoria dos refúgios serve como modelo explicativo para realizar interpretações das paisagens, especialmente no que concerne ao refúgio da fauna e flora, por meio de análises associadas às condições paleoclimáticas. De acordo com Troppmair (1995), os refúgios ou centros de dispersão de fauna e flora não condizem com a realidade tratada pelos naturalistas, como sendo centro de origem das espécies que lhes pertencem, "uma vez que a maioria das espécies originou-se em outras áreas e, graças a processos migratórios de expansão e retração, sofreram distribuição face às mudanças ambientais associadas a paleoclimas".

As alternâncias no Quaternário de climas tropicais úmidos (vigente nas épocas interglaciais), com climas semiáridos (nas épocas glaciais), foram abordados por Bigarella e Salamuni (1961); Bigarella, Marques Filho e Ab'Saber (1961); Bigarella e Andrade (1965) citado por Bigarella (1985). Estes autores contribuíram cientificamente para elaboração da Teoria dos Refúgios Florestais, com a fundamentação baseada nos trabalhos de flutuações climáticas do Quaternário, a partir das evidências paleoclimáticas, que têm como bioindicadores, especialmente, os refúgios de: vegetação do cerrado (savana), linhas-de-pedra, bromélias terrestres e cactáceas.

Dentre outros (MAACK, 1947, apud BIGARELLA, 1971) foi um dos primeiros pesquisadores a levantar as evidências de condições paleoclimáticas no Estado do Paraná. Os estudos, embora sem datação exata, foram baseados nos entulhos de blocos e seixos depositados nas faldas da Serra do Mar, como resultantes da semiaridez existente no período Quaternário.

Geografia Ensino \& Pesquisa, v. 18, n.2 p. 163-174, maio/ago. 2014

Liberali, L.; Ferreira, M. E. M. C. 
Maack dá continuidade aos estudos das implicações causadas pelas flutuações climáticas no Quaternário e, no ano seguinte (1948), sustenta que os campos paranaenses apresentavam-se como encrave que correspondem à fase de clima seco do passado, sendo substituídos pelas massas florestais que ganhavam terreno pela umidificação atmosférica, a ficar as formações rasteiras restritas aos solos de menor fertilidade.

Bigarella (1964) afirma que sob as flutuações climáticas no transcurso do Quaternário, desencadearam os processos com recorrência de expansão e retração das florestas, em função ora do imperativo de um clima mais úmido, ora tendendo a semiaridez. Nas fases de semiari$\mathrm{dez}$, as florestas foram quase totalmente dizimadas, permanecendo em pequenas manchas nos fundos-de-vale em áreas com umidade suficiente para a sua sobrevivência, formando assim refúgios. Portanto, foram esses refúgios que permitiram a existência das florestas, dando a elas no final da fase seca no pleistoceno terminal a possibilidade de expansão em uma época em que as condições ambientais são mais favoráveis, com uma fase mais quente e úmida.

Bigarella (1985) menciona que "nas épocas semiáridas as florestas deixaram de existir, na maior parte do território, restringindo-se a áreas de refúgio onde as condições climáticas locais permitiram sua sobrevivência". Estes refúgios serviram como banco genético para a posterior expansão desta biota. As oscilações climáticas em época de maior ressecamento e com estiagem prolongada, teriam revestido o então quadro paisagístico de florestas, que haviam se reduzido para a expansão e imposição vegetacionais com fisionomias de campos, campo cerrado (savana) e caatinga (savana-estépica).

Contudo, a semiaridez para o Quaternário não pode ser estudada como fato isolado, pois as considerações das flutuações climáticas relacionadas com Teoria dos Refugios Florestais demonstram o extensivo território brasileiro atingido pelas épocas secas impostas por este período geológico. "Como consequência desses eventos, as caatinga (savana-estépicas) e os cerrado (savana)s, teriam se expandido por setores mais amplos do território brasileiro" (CONTI, 1995).

As evidências de clima úmido fez com que os domínios vegetacionais sofressem influência climática e geomorfológica recente, com importante repercussões regionais, especialmente na sua fitofisionomia. Segundo Ab'Saber (1979), a desintegração destas fitofisionomias tropicais, foi desencadeada pelos efeitos paleoclimáticos, especialmente do período Wurm Wisconsin no Brasil. "Este mecanismo perdurou por alguns milhares de anos, com maior incidência entre 13.000-18.000 anos do presente, com possíveis fatos paleogeógrafos e paleoecológicos".

No Brasil, os campos constituíam a formação primitiva e mais antiga, desenvolvendo-se as matas somente no término do Pleistoceno, fato esse que pode ser documentado geologicamente por meio dos depósitos de fanglomerados, de incrustações do Quaternário antigo, dos solos existentes sob a mata. Toda vegetação era composta de gramíneas baixas e de arbustos que constituem cobertura primária do estado do Paraná, isto em uma época indeterminada do Quaternário Antigo (MAACK, 1981).

Neste sentido Viadana (2000), aborda a Teoria dos Refugios Florestais como um procedimento metodológico para os estudos das peculiaridades, especialmente da flora que representa espécies com características diferente embutidas nas florestas inter e subtropicais. Assim, Teoria dos Refugios Florestais, permite o conhecimento a respeito da estrutura super-

Geografia Ensino \& Pesquisa, v. 18, n. 2 p. $163-174$, maio/ago. 2014

O estudo da vegetação xeromórfica e xerofítica na região CentroOcidental Paranaense ficial da paisagem e seus mecanismos fisiológicos, com o objetivo de interpretar os quadros paisagísticos e seus processos a partir do Quaternário antigo, quando existiam diferentes mosaicos distributivos de flora e fauna.

As mudanças ambientais, especialmente na cobertura vegetal do Quaternário antigo, no Paraná, são registradas, por diversos núcleos de cerrado (savana), encravados no meio da floresta estacional semidecidual e onde o angico preto (Piptadenia macrocarpa), geralmente, domina fitofisionomicamente. Contudo, a fitofisionomia deixa claro que essa espécie mencionada 
ocupava áreas bem maiores em épocas passadas, fato confirmado por Bigarella (1985). Para o autor, os vigorosos troncos da copaíba, encontrados como relicto as margens rochosas do rio Paraná (Sete Quedas) e nas proximidades das Cataratas do Iguaçu (tanto no lado brasileiro, como no argentino), sem dúvida, são dos últimos vestígios de cerradão aluvial nesta região.

$\mathrm{Na}$ evolução da flora brasileira durante fases de clima mais seco e semiúmido do Quaternário, a formação vegetal do cerrado (savana) expandia-se pelas regiões Norte, Sudeste e Sul. Dentro do contexto de flora do Sul, o objeto de estudo são espécies de cerrado (savana), Bromeliaceae e Cactaceae no Centro-ocidental e Noroeste do estado do Paraná, que apresentam manchas de cerrado (savana)s relictuais.

Reforçamos que estas espécies de caráter xerófito e xeromórfico, em algumas partes da floresta estacional semidecidual representam provavelmente, formas de relicto do clima semiárido do Quaternário antigo no Paraná. Há disparidade entre o aspecto fisionômico dos campos cerrado (savana)s e o clima atualmente vigente nesta região. Essas afirmações foram realizadas por meio de interpretações das flutuações climáticas que deixaram evidente que no passado predominava um clima semiárido, tendo como registro os refúgios de vegetação do cerrado (savana) embutido nas matas pluviais e subtropicais.

As interpretações do efeito das flutuações climáticas sobre as paisagens, especialmente no Paraná, foram confirmadas por meio de estudos da formação de vegetação aberta (campos cerrado (savanas), bem como por meio de exames de sedimentos coletados no fundo do Atlântico Sul (BIGARELA, 1971). Observou-se, em sedimentos glaciais de idade pleistocênica, uma predominância de pólen de vegetação de campo, sugerindo, então, para o Brasil, uma paisagem constituída por campos cerrado (savana)s ou campos, em detrimento das floresta" (GROOT e GROOT , 1964, citado por BIGARELLA, 1971).

De 1945 a 1953 Maack, desenvolveu simultaneamente estudos por meio de perfil geológico e geográfico e, ainda, sobre a distribuição florística. Por meio dos resultados, elaborou o mapa fitogeográfico do Paraná que permite uma visão geral sobre a distribuição da paisagem de matas e campos, bem como da devastação da cobertura vegetal.

As áreas cobertas por vegetação de cerrado (savana) estão reduzidas no Paraná, embora haja evidências paleobotânicas de que esta formação campestre tenha coberto extensas áreas do Sul do Brasil no Pleistoceno. Um exemplo de evidências paleobotânicas no Paraná é o cerrado (savana) relicto do Guartelá que, segundo Moro (1996), é um ecossistema que parece não ter sofrido muitas modificações em sua estrutura desde o período pleistoceno. A paisagem de cerrado persiste mais ou menos com as mesmas características. E os componentes da associação florística dos campos cerrado no Paraná, correspondem ao revestimento vegetal dos campos do Oeste de São Paulo e do Planalto Central do Brasil.

De acordo com Maack (1968), no Quaternário antigo, os campos limpos e cerrado revestiam grande parte do Paraná como vegetação clímax, de um clima alternante semiárido e semiúmido. Sob as condições climáticas alternantes com precipitações abundantes durante o Quaternário recente, a mata principiou a dominar os campos a partir dos declives das escarpas e dos vales, dos rios, transformando o Estado do Paraná numa das áreas mais ricas em matas do Brasil até poucos decênios.

$\mathrm{Na}$ atualidade, a vegetação de cerrado no Paraná está distribuída em pequenas manchas encravadas nas florestas pluviais. As discussões das causas da distribuição desta vegetação, especialmente no município de Campo Mourão, e suas evidências são diversas. De acordo com Bigarella (1985), a distribuição dos diferentes tipos de vegetação é função das condições edáficas e climáticas. A pluviosidade contribui para que na vegetação original do Paraná predominem as florestas. Os campos e os campos cerrado (savana) encontram-se apenas em áreas edáfica impróprias para o estabelecimento da floresta e ocupavam áreas muito restritas e onde se destacava o cerrado (savana) de Campo Mourão.

Para Stevaux (1996), no Quaternário recente, há 2.000 anos e até hoje, predominam

Geografia Ensino \& Pesquisa, v. 18, n. 2 p. 163-174, maio/ago. 2014

Liberali, L.; Ferreira, M. E. M. C.

ISSN 2236-4994

| 169 
as condições climáticas úmidas. E, ainda, afirma que a mancha de cerrado embutida na mata pluvial em Campo Mourão são evidências de condições ambientais diferentes das atuais. Com isso, conforma-se que os últimos vestígios de cerrado ocorrem em Campo Mourão Paraná, (FERRI,1977).

Este autor, em seus estudos sobre as mudanças ambientais do Quaternário, afirma que os registros "fósseis marinhos que ocorrem em Ponta Grossa; Varvitos - rocha sedimentar de origem glacial - em Itu; dunas arenosas recobertas de vegetação que margeiam o rio São Francisco; mancha de cerrado (savana) embutida na mata pluvial em Campo Mourão, são evidências de condições ambientais diferentes das atuais, mas em tempo geológico distintos. São relíquias de condições climáticas e tectônicas que mudaram durante a evolução do planeta" (Stevaux, 1998).

A vegetação de cerrado (savana) de Campo Mourão é um dos refúgios que se encontra em latitudes subtropicais. Este município situa-se em uma área de interflúvio, e isto dificultou a cobertura total de floresta nesta área. Portanto de acordo com Bigarella (1971), esses acontecimentos ocorreram nesta última fase úmida, e a floresta se expandiu a partir dos fundos de vales (vales dos Rios Ivaí e Piquiri), onde se refugiava nas épocas secas.

\section{Os enclaves nas unidades fitogeográficas de cerrado, floresta estacional semide- cidual e floresta ombrófila mista}

A fitogeografia de enclave, refere-se à formação de vegetação de cerrado e espécies de Bromeliaceae e Cactaceae. As referidas formações e espécies encontram-se assim espacializadas: a flora do cerrado, composta por espécie de Bromeliaceae, são encontradas nos pontos 2 e 3 no municípios de Campo Mourão e no ponto 1, no município de Tuneiras do Oeste. Quanto à distribuição das Cactaceae, identificou-se em alguns pontos em afloramento rochosos, juntamente com as Bromeliaceae, nos pontos 4 e 6 no município de Campo Mourão e no ponto 5, no município de Luiziana,

Verificou-se, in loco, através dos levantamentos fitogeográficos, a presença de enclave de vegetação rupestre, fitofisionomicamente xerófitos, representados pelas espécies de cactáceas e bromeliáceas, adaptadas à sobrevivência em ambientes rochosos, com pouco solo e pobre em nutrientes. Isso ocorre em porções de contato entre as áreas dos afloramentos rochosos e algumas espécies da Floresta Estacional semidecidual. Na área de transição do solo Neossolo Litólico e o Organossolos registraram-se a ocorrência dos Cereus hildmannianus, K. Schumann (mandacaru) seja em ambientes heliófitos, eventualmente, em ambiente mesófitos nos enclaves pesquisados. Já a Bromelia balansae Mez (gravatá), ocorre quase sempre nas áreas entremeadas com vegetação de porte arbóreo e arbustivo, tanto no enclave de cerrado, quanto no enclave de Bromeliaceae e Cactaceae nos afloramentos rochosos.

Nos pontos referenciados, os levantamentos fitogeográficos foram realizados com recorte espacial para o estudo das espécies de Cactáceas, Bromeliáceas e de espécies do cerrado. Nos estudos da distribuição da flora, encontraram-se enclaves de vegetação rupestre, fitofisionomicamente xerófito (figura 02) (estas 4 fotos são todas de um ponto somente? De quais

Geografia Ensino \& Pesquisa, v. 18, n. 2 p. 163-174, maio/ago. 2014

O estudo da vegetação xeromórfica e xerofítica na região CentroOcidental Paranaense pontos foram tirado? Muito importante a foto do Pequizeiro), representativos de espécies adaptadas à sobrevivência em ambientes rochosos, com pouco solo e pobre em nutriente. Encontraram-se ainda as xeromórficas, adaptadas em nichos que passaram por longos períodos de seca, por meio de seus mecanismos bastantes característicos no município de Campo Mourão como, por exemplo, o xilopódio. Nas porções de contato, entre os afloramentos rochosos e a espécies da formação Estacional Semidecidual, ocorrem espécies de Cereus hildmannianus K. Schumann (mandacaru) e, nas áreas com sombreamento, Bromelia balansae Mez (gravatá). 
O estudo fitogeográfico das áreas compreendidas, a saber: Estação Ecológica do Cerrado, Parque Estadual Lago Azul, cerrado Cipauto, afloramento rochoso Nishida, área de cerrado de Tuneiras do Oeste e afloramento em Luiziana; serem estas áreas compostas por espécies vegetais de Cerrado, Bromeliaceae e Cactaceae, perfazendo um total 528.481,43 $\mathrm{m}^{2}$ (52,32 Ha). Essas áreas, com enclave de espécies, indicam de uma organização da paisagem diferente com relictos de condições ambientais pretéritas.

Observou-se que os enclaves estão distribuídos em nichos vegetais disjuntos, inseridos nas unidades fitogeográficas Floresta Estacional Semidecidual e Floresta Ombrófila Mista. No estudo dessas áreas de afloramentos, os solos apresentam-se como Neossolos Litólico e Cambissolos e, nas áreas com vegetação de cerrado e Bromelia balansae, o Latossolo Vermelho Distroférrico - em Campo Mourão e, Argissolo Vermelho Distrófico em Tuneiras do Oeste.

Figura 2-Localização dos Municípios de Tuneiras do Oeste, Campo Mourão e Luiziana
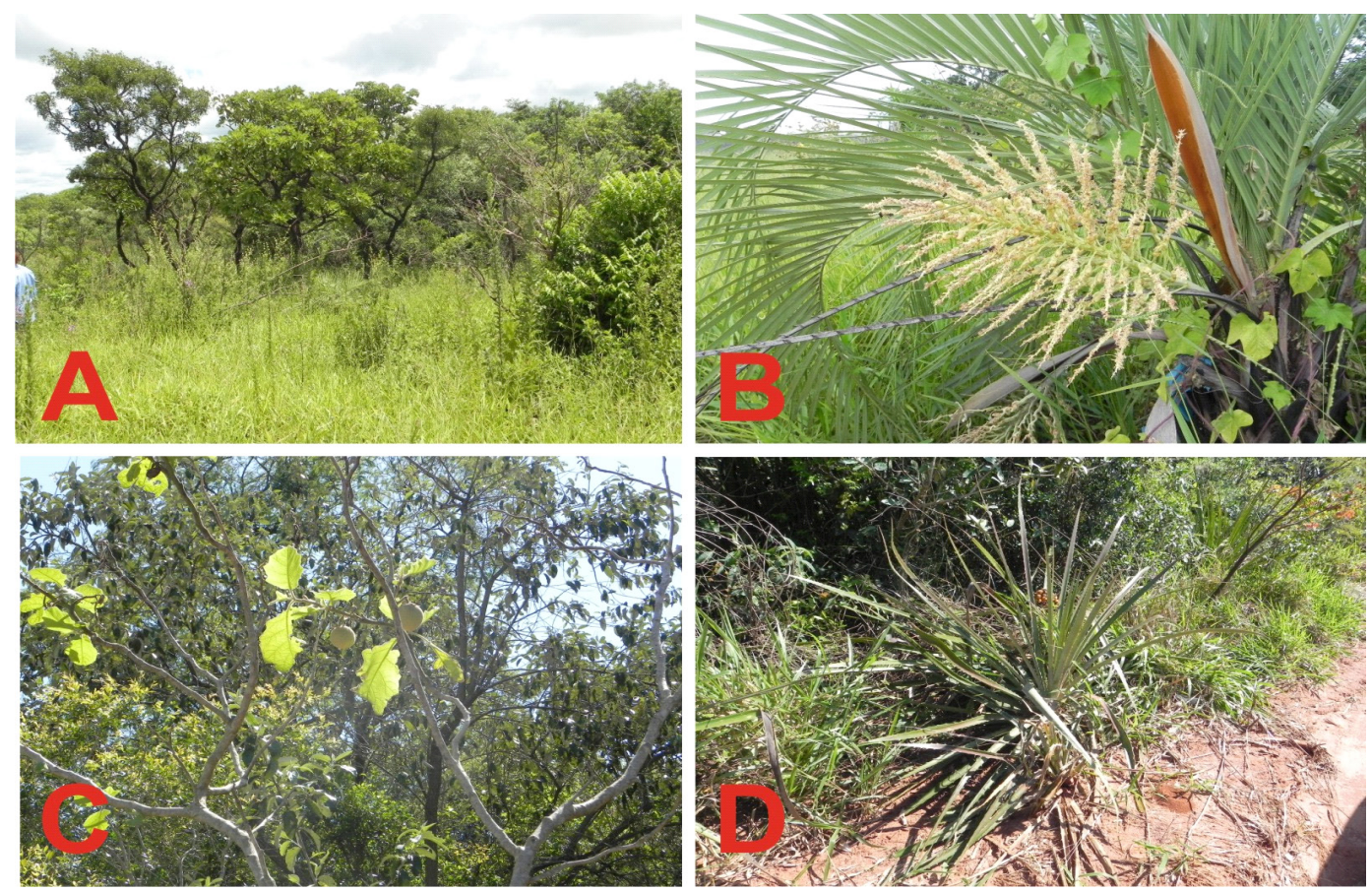

Fonte: Fotografias de José Renato Augusto e Lucimara Liberali, 2013.

Os encraves das áreas de estudo de Campo Mourão, Tuneiras do Oeste e Luiziana, representadas nos pontos 1,2,3,4,5 e 6 encontram-se em fragmentos. Essa fragmentação tanto pode ter ocorrido por ação das condições antrópicas atuais, como de possibilidade de fragmentação, condicionada aos períodos cíclicos glacial e interglacial. Portanto, entende-se por fragmentação uma área reduzida (enclave), ou mesmo dividida em fragmentos (entremeada a outras paisagens).

No levantamento fitogeográfico realizado nos pontos 1, 2 e 3, verificou-se que mesmo estando essas áreas reduzidas, elas sofreram e ainda sofrem, com a pressão antrópica que ameaça esses enclaves e, também, devido ao desenvolvimento expansionista e econômico das atividades agrícolas e urbana. Observou-se que mesmo com a degradação antrópica sofrida, com alteração de seu ecossistema, os fragmentos ainda são bastante representativos e resguardam uma flora representada por inúmeras famílias e espécies. Dessas classificaram-se 52 famílias, distribuídas em 122 espécies, além de 13 identificadas apenas em nível de gênero.

Ainda, neste estudo, verificou-se que 12 espécies identificadas na área de estudo, constam da lista vermelha de plantas ameaçadas de extinção no Paraná. São consideradas raras e

Geografia Ensino \& Pesquisa, v. 18, n. 2 p. $163-174$, maio/ago. 2014

Liberali, L.; Ferreira, M. E. M. C.

ISSN 2236-4994 171 
ameaçadas em algum grau, conforme (Hatschbach \& Ziller 1995): na categoria "rara" encontra-se as espécies: Annona coriacea Mart., Duguetia furfaraceae Stryphnodendron adstringens, Cayaponia espelina, Dalechampia trichophila, Campomanesia pubescens, Passiflora miersii Mart. Na categoria em perigo destaca-se, Butia paraguayensis, Cerastosanthes bilariana Cogn., Strychnos rubiginos. Na categoria vulnerável verificou-se o Caryocar brasiliense Camb e a Talisia angustifolia Radlk.

Os resultados obtidos corroboram com os estudos de Vanzolini (1970). Ao referir-se aos refúgios ecológicos biótopo de vegetação relictual (biocenose), explicita o mecanismo corretamente aceito para a quase totalidade dos casos - o da especiação geográfica, por meio da fragmentação. Neste caso, o fenômeno pode ter ocorrido por meio das flutuações climática do Quaternário. Contudo, esses resultados necessitariam de estudos mais aprofundados, exigência que demandaria maior tempo para confirmação.

\section{Considerações finais}

O estudo aplicado as áreas ecotonais nos Municípios de Tuneiras do Oeste, Luiziana e Campo Mourão verificou que, as entidades taxonômicas diferem por caracteres ecológicos, ligados ao clima, habitats diferentes e afloramentos rochosos.

Nos estudos de campo, verificou-se que os afloramentos rochosos constituem uma biocenose. A última abriga espécies de estrutura bastante frágil, pois as condições ecológicas apresentam, na maioria das vezes: solos pouco desenvolvidos, deficiência de drenagem e insolação direta. Esses fatores adversos dificultam a adaptação da formação vegetal, que se fixa nas fraturas das rochas. Este fato foi observado, especialmente na área de estudo, em que a formação rochosa constitui-se de basalto, rocha ígnea extrusiva.

O ambiente do afloramento rochoso propicia, atualmente, a garantia de existência das plantas xerofíticas, por meio de um banco genético que já ocupou área mais extensa na atualidade, essas plantas vivem sob a forma de refúgio na floresta estacional semidecidual. E, ainda, em áreas de declividade que dificultaram a ação antrópica.

Constatou-se no enclave de cerrado que parte das ervas e arbustos possuem xilopódios (órgãos armazenadores de água, sem utilidade no clima atual). Essa ocorrência indica a presença de condições semiáridas, ou de estiagem prolongada, ou ainda, de suscetibilidade ao fogo. As atuais condições fitofisionômica dessas espécies atestam que elas estão em local impróprios, considerando-se as suas condições geoecológicas.

As mudanças ambientais geradas pelos períodos cíclicos climáticos influenciaram na especiação, ao longo do tempo e do espaço, na área de estudo que abrange os municípios de Campo Mourão, Luiziana e Tuneiras do Oeste. Esses períodos cíclicos climáticos são importantes para entender a permanência de espécies vegetais de condições adversas à atual.

Diante destes fatos observou que a formação dos enclaves estudados está relacionado as flutuações climáticas do Quaternário, por sua vez, podem ter influenciado a ocorrência e permanência das espécies de Bromélia, Cactaceae e cerrado, nos municípios de Campo Mourão, Luiziana e Tuneiras do Oeste.

Geografia Ensino \& Pesquisa, v. 18 n. 2 p. 163-174, maio/ago. 2014

O estudo da vegetação xeromórfica e xerofítica na região CentroOcidental Paranaense

\section{Referências}

AB'SABER, A.N. O Domínio Morfoclimático Semiárido das Caatinga (Savana-Estépica) Brasileiras, Geomorfologia, São Paulo, Instituto de Geografia, Universidade de São Paulo, n. 43, 1974.

AB'SABER, A.N.,. Revisão dos Conhecimentos Sobre o Horizonte Sub-Superficial de Cascalhos Inhuma- 
dos Do Brasil Oriental. Notícia Geomorfológica, Campinas, v. 6, n. 11, 1966. [Publicado originalmente em Boletim da Universidade do Paraná, Curitiba, v. 2, p. 2-32, 1962.]

AB'SÁBER, A. N. Cerrado (savana)s e Mandacarus: área de Salto-Itu é referência para investigações envolvendo condições climáticas do passado. Scientific American Brasil, São Paulo, v. 1, n. 4, 2002.

AB'SÁBER, A. N. Redutos Florestais, Refúgios de Fauna e Refúgios de Homens. Revista de Arqueologia, São Paulo, v. 8, n. 2, 1994-1995.

AB'SABER, A. N. A organização natural das paisagens inter e subtropicais brasileiras. In: Ferri MG (coord.) Anais... III Simpósio sobre o cerrado (savana). São Paulo, Edgard Blucher /EDUSP, 1971.

AB'SABER, A.N. Espaços ocupados pela expansão dos climassecos na América do Sul, por ocasião dos períodos glaciais Quaternários. Paleoclimas, São Paulo, v.3, 1977.

ANDRADE-LIMA, D. Present-day forest refuges in northeastern Brazil. In: G. T. Prance (ed.) Biological diversification in the tropics. Columbia Univ. Press, New York, 1982

BIGARELLA, J. J. e MAZUCHOWSKI, J. Z., Visão Integrada da Problemática da Erosão, In: Anais... $3^{\circ}$ Simpósio Nacional de Controle da Erosão, Maringá - Paraná, Livro Guia, 1985.

BIGARELLA, J.J. e BECKER, International Symposium on the Quaternary. Curitiba: UFPR, Bol. Paran. Geociên. 33, 370 p., 1975.

BIGARELLA, J.J. Variações Climáticas no Quaternário e Suas, Implicações no Revestimento Florístico do Paraná. Boletim Paranaense de Geografia, março-1964, Curitiba, 1971.

BOLZON, R.T., MARCHIORI, J.N.C. A vegetação no sul da América -Perspectiva paleoflorística. Ciência \& Ambiente, Santa Maria, n. 24, p. 5-24, 2002.

COLINVAUX, P.A., OLIVEIRA, P.E. e BUSH, M. (2000) Amazonian and Neotropical plant communities on glacial timescales: the failure of the aridity and refuge hypothesis.Quaternary Science Reviews, 2000

CONTI, J.B e FURLAN S.A. Geoecologia. O clima, os solos e a biota. In: ROSS, J. L. S.Geografia do Brasil. São Paulo:Edusp, 1996.

CONTI, J.B. Desertificação nos Trópicos (proposta de metodologia de estudo aplicada ao nordeste Brasileiro). Tese de Livre-Docência. São Paulo: FFLCH-USP, 1995.

EMBRAPA. Sistema Brasileiro de Classificação de Solos. Embrapa Solos, Rio de Janeiro, 2008.

FERREIRA, J. C. V., Municípios paranaenses: origens e significados. - Curitiba : Secretaria de Estado da Cultura, 2006.

FERRI, M.G. Ecologia do Cerrado. In: Anais... IV Simpósio o Cerrado: bases para utilização agropecuária. EDUSP, São Paulo, 1977.

GROOT, J. J. \& GROOT, C. B. Quaternary stratigraphy of sediments of the Argentine Basin- a palynological investigation. N.Y Acad. Sci. Trans., New York, 26; 881-886, Ser., 1964.

HAFFER, J.; PRANCE, G. T. Impulsos climáticos da evolução na Amazônia durante o Cenozóico: sobre a teoria dos Refúgios da diferenciação biótica. Estudos Avançados, v.16, n.46, p.175-206, set./dez. 2002.

HAFFER, J. Ciclos de tempo e indicadores de tempos na história da Amazônia. Revista Estudos Avançados, n. 15, v. 6, São Paulo, IEA-USP, maio/jun.1992.

HATSCHBACH, G. \& ZILLER, S. Lista vermelha de plantas ameaçadas de extinção no Estado do Paraná. SEMA/GTZ, Curitiba, 1995

HESPANHOL, Antonio Nivaldo. A formação sócio-espacial da região de Campo Mourão e dos municípios de Ubiratã, Campina da Lagoa e Nova Cantu-Pr. Boletim de Geografia. Maringá: UEM - Ano 11, nº 01, dezembro, 1993.

HUECK, K. As florestas da América do Sul: ecologia, composição e importância econômica. Editora da Universidade de Brasília e Editora Polígono, São Paulo, 1972.

IAP - INSTITUTO AMBIENTAL DO PARANÁ. Plano de Manejo do Parque Estadual Lago Azul: Encarte III - Análise do Parque Estadual Lago Azul. / Instituto Ambiental do Paraná, Diretoria de Biodiversidade e Áreas Protegidas. (Agosto, 2005) - Curitiba: IAP/DIBAP, 2005. Disponível em: http://www.uc.pr.gov.br/arquivos/File/Plano_de_Manejo/Parque_Estadual_Lago_Azul/5_PELA_ENCARTE_I II.pdf > . Acesso em: 19 set. 2013.

Geografia Ensino \& Pesquisa, v. 18, n.2 p. 163-174, maio/ago. 2014

Liberali, L.; Ferreira, M. E. M. C. 173 
KNAPP, S. e MALLET, J. Refuting Refugia? Science, 2003.

LIBERALI, L. Estudo Fitossociológico da Vegetação do Cerrado de Campo Mourão. 2003. Dissertação (Mestrado em Geografia). Maringá, Paraná: Universidade Estadual de Maringá, 2003.

LUZ, F. O Fenômeno Urbano numa região Pioneira: Maringá. Dissertação de Mestrado. Universidade de São Paulo. 1980.

MAACK, R. Geografia Física do Estado do Paraná. Rio de Janeiro, Livraria José Olympio Editora S/A. $2^{\text {a }}$ ed., p 248-255. 1981.

MASSOQUIM, N. G. ; Azevedo, T. R. Interferência de Fenômenos Climáticos em Culturas Temporárias na Microrregião de Campo Mourão. Revista de Geografia, Meio Ambiente e Ensino - GEOMAE (Impresso), v. 1, p. 13-28, 2010.

Mineropar. Minerais do Paraná S/A. Carta geológica. Folha Campo Mourão SG.22-V-B. 2006.

Mineropar. Minerais do Paraná S/A. Carta geológica. Folha Umuarama, SF 22-Y-C.2006

RODERJAN, C. V.; GALVÃO, F; KUNIYOSHI, Y. S.; HATSCHBACH, G. G. As unidades fitogeográficas do estado do Paraná. Ciência\&Ambiente, Santa Maria: Universidade Federal de Santa Maria, n. 24, p. 75-92, 2002.

SILVEIRA, H. ; OLIVEIRA, D. L. A. ; ANDRADE, A. A. ; SILVA, A. V. Avaliação de algumas características físicas e químicas de Latossolos sob vegetação relictual de Cerrado (savana) e plantio direto em Campo Mourão - PR. Boletim de Geografia, Maringá, v. 1, n.1, p. 21-31, 2002.

STEVAUX, J. C. Mudanças Ambientais no Quaternário. Fundamentos da Geografia Contemporânea. In Faculdade Estadual de Ciências e Letras de Campo Mourão, Curso de Especialização em Geografia 1998.

STEVAUX, J. C. Mudanças ambientais no Quaternário. Fundamentos da Geografia Contemporânea. In: Faculdade Estadual de Ciências e Letras de Campo Mourão, curso de especialização em geografia. 1996.

STODDART, D. R. Organismo e ecossistema como modelos geográficos. São Paulo: Livros Técnicos e Científicos S. A. e Ed. da USP, 1974.

TROPPMAIR, H. Biogeografia e Meio Ambiente. 4. ed. do Autor, Rio Claro, 1995

TROPPMAIR, H. Biogeografia e Meio Ambiente. 6. ed. Rio Claro: Divisa, 2004

TROPPMAIR. H. Biogeografia e meio ambiente. 8a ed. Rio Claro, São Paulo: Divisa, 2008.

VANZOLINI, P. E. Zoologia Sistemática, Geografia e a origem das espécies. São Paulo: Universidade de São Paulo, Instituto de Geografia, 1970.

VEIGA, P. Estrada boiadeira- conquista de Mato Grosso. 15 nov. 2009. Disponível em: < http://pedrodaveiga.blogspot.com.br/2009/11/estrada-boiadeira-conquista-de-mato.htm>1, Acesso em: 13/07/2012.

VIADANA, A. G. A Teoria dos Refúgios Florestais Aplicada ao Estado de São Paulo. Tese de Livre-

-Docência. Rio Claro - UNESP, 2000.

\section{Correspondência}

\section{Joalana Araujo Macedo}

Geografia Ensino \& Pesquisa, v. 18 n. 2 p. $163-174$, maio/ago. 2014

O estudo da vegetação xeromórfica e xerofítica na região CentroOcidental Paranaense
E-mail: joalanamacedo@yahoo.com.br

Recebido em 7 de fevereiro de 2014.

Revisado pelo autor em 30 de julho de 2014.

Aceito para publicação em 28 de agosto de 2014. 